\title{
A QUALIDADE DA EDUCAÇÃO BRASILEIRA COMO DIREITO
}

\author{
Carlos Roberto Jamil Cury*
}

\begin{abstract}
RESUMO: A qualidade em educação sempre foi uma dimensão esperada da parte de todos os envolvidos em sistemas educacionais. Entretanto, nos anos noventa, a chamada "cultura de avaliação" impôs avaliaçóes de larga escala com testes padronizados a fim de medir o desempenho dos estudantes. No Brasil, país de democratização educacional tardia, o acesso e a permanência ao ensino obrigatório foram vistos como básicos para a qualidade do desempenho. Ora, a qualidade depende de insumos pedagógicos, da formação inicial e continuada dos docentes, de planos de carreira e de salários atrativos. Tais exigências, dentro de um país federativo, estáo contempladas no novo plano nacional de educação em que se avançou no encaminhamento no regime de colaboração.
\end{abstract}

Palavras-chave: Educação, Qualidade e Regime de Colaboração. Educação e Sistemas Educacionais. Qualidade e Avaliação.

\section{BRASILIAN EDUCATION QUALITY AS A RIGHT}

ABSTRACT: Quality in education has always been an expected dimension by all those involved in educational systems. In the nineties, however, the so called "evaluation culture" imposed large scale evaluations by means of standardized tests in order to measure students' performance. In Brazil, a country of a late educational democratization, the admission and permanence in compulsory schooling was considered essential for the quality of performance. Nevertheless, such quality depends on pedagogical input, initial and continuing education, career plans and attractive wages. Such requirements, in a federative country, are contemplated in the new national education plan which shows some improvement regarding collaboration among the federative entities.

Keywords: Education, quality and collaboration regime. Education and educational systems. Quality and educational evaluation.

\section{LA QUALITÉ DE L'ÉDUCATION BRÉSILIENNE COMME DROIT}

RESUMÉ: La qualité de l'éducation a toujours été une dimension attendue de la part de tous les concernés dans les systèmes scolaires. Néanmoins,

* Pontifícia Universidade Católica de Minas Gerais, Instituto de Ciências Humanas, Departamento de Educação, Belo Horizonte, MG, Brasil. E-mail de contato: crjcury.bh@terra.com.br 
pendant les années quatre-vingt-dix, la dite "culture d'évaluation" a imposé des évaluations en large échelle avec de tests standardisés à fin de mesurer la performance des éléves. Au Brésil, pays de démocratisation scolaire tardive, l'accès et la permanence dans l'enseignement obligatoire ont été vus comme fondamentaux pour la qualité de la performance. Or, la qualité dépend des inputs pédagogiques, de la formation initiale et continue des enseignants, de plans de carrière et de salaires attrayants. Telles exigences dans un pays fédératif sont envisagées dans le nouveau plan national de l'éducation dans lequel il y a eu un progrès dans le régime de collaboration entre les l'États de la fédération.

Mots-clés: Éducation, qualité et régime de collaboration. Éducation et systèmes d'éducation. Qualité et évaluation.

\section{Introdução}

A

qualidade é algo que, na linguagem comum, tem sido considerado como uma agregação que confere valor superior a um bem, a um serviço ou a um sujeito. Trata-se de um atributo ou predicado virtuoso pelo qual esse sujeito, bem ou serviço se distingue de outros semelhantes considerados ordinários. Ela caracteriza e distingue algo ou alguém como por uma certa propriedade que lhe é inerente. A qualidade também pode ser apontada como capacidade para efetuar uma ação ou atingir uma certa finalidade.

O termo qualidade advém do latim qualitas, mas cuja procedência mais funda é a de poiótês do grego e que significa um título definidor de uma categorização ou classificação. De certo modo, estamos no campo de um atributo distintivo de um bem que passa a se apresentar com uma característica particular além da comum. Por vezes, essa distinção costuma ser assinalada com uma adjetivação como no caso de qualidade social, qualidade total, entre outras.

A qualidade, até por essa origem greco-latina, é um termo polissêmico e cuja definiçáo não só carece de uniformidade como também se louva em sentidos de muita complexidade.

Caso se peça à filosofia uma determinação mais precisa do que seja a qualidade, pode-se dizer que, considerando vários autores como Aristóteles, Kant e Engels, ela supóe uma certa quantidade capaz de ser mensurada, na qual reside um modo de ser de tal forma distinta que ela se veja enriquecida ao ponto de sua realidade apresentar um salto agregando valor àquilo que a sustém. E essa realidade qualificada pode ser conhecida pelo sujeito que pode então agir sobre ela. Essa indicação definidora da qualidade, ainda que ela mesma se preste a muitas outras determinaçóes, pode nos ser útil no desvendamento de aspectos da educação escolar. 
Ora, é notória a dificuldade em se obter uma definição precisa do que seja qualidade. Desse modo, pode-se partir daquilo que a qualidade não é: uma espécie de definição negativa. São as barreiras excludentes da desigualdade social inclusive legais como era o caso dos exames de admissão, a discriminação que desigualava o ensino profissional, os limites do ensino não-gratuito e a descontinuidade administrativa. A não qualidade se expressou e ainda está presente nas repetências sucessivas redundando nas reprovaçóes seguidas do desencanto, da evasão e abandono. Como diz Oliveira (2006): “[...] passávamos da exclusão da escola para a exclusão na escola”.

A qualidade não é a falta de acesso, não é o aligeira mento não é a carência de recursos e, sobretudo, não é a saída dos egressos sem o domínio daquilo que a LDB considera como formação comum (art. 22) e formação básica do cidadão (art. 32) e respectivos objetivos e finalidades (art. 32 e art. 35).

Partir de um solo positivado, formalmente seguro, é sempre uma via para se abraçar esta temática. Aliás faz jus a uma trajetória da área que, por meio de suas associaçôes, aí compreendida o Cedes, jamais secundarizou o papel da legislação na consecução de valores e objetivos maiores para a educação.

\section{A qualidade no ordenamento jurídico}

A Constituição Federal de 1988 põe direito de todos, isto é, dispóe para todos a titularidade do direito à educação. Este direito, segundo o artigo 6o, Título II, Capítulo II da Constituição, a acolhe dentro dos Direitos e Garantias Fundamentais. Isto significa, em outros termos, que ela foi positivada dentro de uma Constituição e, portanto, passa a fazer parte do estatuto de um Estado Nacional. São elementos constituintes da cidadania.

Embora longa, cumpre trazer uma citação de Ranieri (2013), pelo seu caráter claro, direto e fundamentado. Segundo ela, a educação básica, no âmbito da esfera pública:

[...] goza, como direito fundamental, das prerrogativas de imprescritibilidade, inalienabilidade, irrenunciabilidade, inviolabilidade, universalidade, efetividade, interdependência e complementaridade. Exemplificando. $\mathrm{O}$ direito não se perde por decurso de prazo (v.g., a educação básica obrigatória e gratuita é assegurada para todos os que a ela não tiveram acesso na idade própria, CF, art. 208, I); náo pode ser violado, sob pena de responsabilização administrativa, civil e criminal (o náo oferecimento do ensino obrigatório pelo poder público ou sua oferta irregular importa responsabilidade da autoridade competente, assim como é dever dos pais e responsáveis zelar pela frequência 
à escola, CF, art. 208, $\$ \$ 1$ o e 2o); é universal (art. 208, I e II), supóe a atuação do Poder Público e o recurso a meios coercitivos para impor sua execução, caso necessário (ação judicial prevista no art. 5 o da Lei de Diretrizes e Bases da Educação - LDB, lei n. 9.394/96, de 20/12/1996), é interdependente e complementar a outras previsóes constitucionais (a Educaçáo tem papel fundamental no desenvolvimento nacional, na construção de uma sociedade justa e solidária - CF, art. 3o - e no desenvolvimento da pessoa para o exercício dos demais direitos civis, políticos, econômicos, sociais e culturais - CF, 205; em relação à criança e ao adolescente, a Educação é direito e dever de absoluta prioridade - CF, art. 227 etc.) $\mathrm{O}$ direito à educação, adicionalmente, é dever fundamental da família e do Estado, mas, sobretudo do indivíduo. (p. 76)

Esta citação evidencia, por si, e em comparação com outros tempos, o avanço formalizado em lei.

A Constituição de 1946, no art. 172, cobrava dos sistemas e dos alunos eficiência escolar. A Lei n. 4.024/61 atribuía ao MEC a função de zelar pela qualidade do ensino em todo o país, cabendo aos Conselhos de Educação o papel de melhorar a qualidade e elevar os indices de produtividade do ensino. Já alteração promovida nessa última lei pela Lei n. 5.692/71 pedia por avanços progressivos dos alunos e cobra dos mesmos um rendimento escolar (Art. 14).

Se a educação escolar, assim, tornou-se um direito da cidadania de modo ampliado, ele veio a ser ainda mais largo quando o Brasil se torna signatário de vários Tratados e Convençôes Internacionais relativos aos direitos humanos dos quais a educação faz parte. Eis que a Constituição do Brasil, promulgada em 1988, em seu art. $4^{\circ}$ estabelece uma dialética entre o nacional e internacional onde se destacam princípios como prevalência dos direitos humanos e cooperação entre os povos para o progresso da humanidade.

Após a emenda constitucional n. 45/2004, o art. 5º da Constituição de $1988, \$ 30$, ganhou um parágrafo assim redigido ${ }^{1}$

$\$ 3^{0}$ - Os tratados e convençóes internacionais sobre os direitos humanos que forem aprovados, em cada Casa do Congresso Nacional, em dois turnos, por três quintos dos votos dos respectivos membros seráo equivalentes às emendas constitucionais.

Assim, os tratados e convenções, posteriores a dezembro de 2004, versando sobre os direitos humanos terão o caráter de constitucionalidade e dotados de eficácia constitucional. 
Este campo do direito internacional procura colocar em evidência os direitos humanos a fim de prevenir novas violaçôes e orientar a ordem internacional. O direito internacional relativo aos direitos humanos requer que o conhecimento e a observação de tais direitos sejam difundidos e se vejam garantidos por meio de uma regulação internacional consensual.

Tal direito substitui a visão hobbesiana da cidadania calcada sobre o Estado-Nação por uma visão kantiana fundada sobre a cidadania universal. Esta substituição é recente e suas orientações se apoiam e se afirmam desde a Declaração Universal dos Direitos Humanos de 1948, a qual reconhece os direitos fundamentais para todos.

É por isso que a Organização das Naçôes Unidas (ONU), organismo de vocaçáo internacional, em 10/12/1948, proclama a Declaração Universal dos Direitos Humanos como expressão do reconhecimento da dignidade inerente a todos os membros da família humana e de seus direitos iguais e inalienáveis. Ou, como já afirmava Hegel, no século XIX:

É parte da educação do pensamento como consciência da singularidade, na forma da universalidade, que o Eu começa a ser apreendido como uma pessoa universal no qual tudo é idêntico. Um homem vale como homem em virtude de sua humanidade, não porque é judeu, católico, protestante, alemão, italiano etc. Essa é uma assertiva que o pensamento ratifica e ser consciente disso tem uma importância infinita. Isso só é deletério quando isso é cristalizado, por exemplo como um cosmopolitismo em oposição à vida concreta do Estado. [Tradução livre do autor].

Nesse sentido, para não se cristalizar em figuras abstratas e sem efetividade, esse cosmopolitismo dos direitos humanos deve começar a ser respeitado no âmbito tradicional dos Estados Nacionais, deles não podendo eximir-se.

Como diz o Prefácio à terceira versão do Programa Nacional de Direitos Humanos (PNDH) do Decreto n. 7.177/2010 da Secretaria Especial de Direitos Humanos:

A terceira versão do Programa Nacional de Direitos Humanos - PNDH-3 - representa mais um passo largo nesse processo histórico de consolidação das orientaçóes para concretizar a promoção dos Direitos Humanos no Brasil. Entre seus avanços mais robustos, destaca-se a transversalidade e inter-ministerialidade de suas diretrizes, de seus objetivos estratégicos e de suas açôes.

A educação em Direitos Humanos pretende a criaçáo de uma cultura que, junto com outros marcos legais, faça avançar o que a Constituição prevê e 
também o que demanda a consciência universal contemporânea. Nesse sentido, o PNDH/2010 do Decreto n. 7.177/10, em seus múltiplos objetivos gerais, destaca a inclusão da educação e cultura em direitos humanos nas instituiçóes escolares da educação básica e em instituiçôes formadoras. Entre as açôes programáticas em articulação com o MEC e os sistemas de educação há esta:

a) Estabelecer diretrizes curriculares para todos os níveis e modalidades de ensino da educação básica para a inclusão da temática de educação e cultura em Direitos Humanos, promovendo o reconhecimento e o respeito das diversidades de gênero, orientação sexual, identidade de gênero, geracional, étnico-racial, religiosa, com educação igualitária, não discriminatória e democrática.

Só em um planeta mundializado onde se possa realizar da essência da humanidade, pondo-se ênfase no que é comum à espécie humana, é que a superioridade axiológica da humanidade vista ut genus sobrepor-se-á uma visada dos países vistos como naçôes particulares.

O próprio nome da declaração ilustra bem a missão que lhe é inerente: fazer com que todos os Estados signatários protejam e ponham em prática os valores universais próprios dos seres humanos, à luz de uma regulação universal. ${ }^{2}$

Este núcleo fundador abriu as portas para outros tratados internacionais, os quais, não raro, conhecem dimensōes complementares por meio de tratados regionais. E, por meio destes instrumentos internacionais, que se pode ter um controle judiciário dos direitos humanos e das liberdades fundamentais.

Cumpre concordar com a distinção feita por Bovero (2002, p. 130):

[...] se os direitos do homem (da pessoa) são propriamente universais, ou seja, cabem a qualquer um como pessoa, os direitos do cidadão são necessariamente particulares, ao menos enquanto não seja instituída uma cidadania universal, cosmopolita.

A efetivação destes princípios se mede por fatos e não apenas por normas legais ainda que imperativas. Este é um caminho difícil. Vale a advertência de Bobbio (1992, p. 45):

Creio que uma discussão sobre os direitos humanos deve hoje levar em conta, para não correr o risco de se tornar acadêmica, todas as dificuldades procedimentais e substantivas, às quais me referi brevemente. A efetivação de uma maior proteção aos direitos do homem está ligada ao desenvolvimento global da civilização humana. É um problema que não pode ser isolado, sob pena não digo de não resolvê-lo, mas de sequer compreendê-lo 
em sua real dimensão. Quem o isola já o perdeu. Não se pode pôr o problema dos direitos do homem abstraindo-o dos dois grandes problemas do nosso tempo, que são os problemas da guerra e da miséria, do absurdo contraste entre o excesso de potência que criou as condiçóes para uma guerra exterminadora e o excesso de impotência que condena grandes massas humanas à fome. Só nesse contexto é que podemos nos aproximar do problema dos direitos com senso de realismo.

Se tal é a importância da educação, então, ela só pode ter como própria de sua natureza a qualidade. Tanto é assim que este direito, assim juridicamente protegido, se vê ainda cercado de um financiamento vinculado à própria Constituição de modo que, pelo art. 212, todos os entes federados são obrigados a fazer o devido investimento em educação a fim de assegurar sua qualidade. Qualidade esta que se torna princípio do ensino quando o art. 206, VII, assevera a garantia de padrão de qualidade. Este princípio é retomado no art. 3o, IX, da lei de diretrizes e bases da educação nacional e mais especificado no art. 4o, IX, no qual se nomina o que são padróes mínimos de qualidade de ensino, definidos como a variedade e quantidade minimas, por aluno, de insumos indispensáveis ao desenvolvimento do processo de ensino-aprendizagem. Mais adiante o art. 74 vai indicar uma base capaz de assegurar ensino de qualidade: padrão minimo de oportunidades educacionais e custo minimo por aluno.

Enfim, o art. 75 implica a União e os Estados em sua função supletiva e redistributiva de modo a garantir o padráo minimo de qualidade do ensino. As Diretrizes e Bases da Educação Nacional, lei n. 9.394/96, que, entre outras funçóes, terá de explicitar os artigos constitucionais, vai pontuar 10 vezes o termo qualidade, seja como padrão de qualidade, padrão mínimo de qualidade, avaliação de qualidade, melhoria da qualidade, aprimoramento da qualidade e ensino de qualidade. $^{3}$

O horizonte constitucional de um pleno desenvolvimento da pessoa, seu preparo para a cidadania e qualificação para o trabalho se tensiona, no próprio texto, com uma realidade que não lhe é estranha, quando o art. 214, III, o do Plano Nacional de Educação, dispóe que as açóes integradas dos poderes públicos deve conduzir a uma melhoria da qualidade do ensino. Afinal, a educação, partícipe das relaçôes sociais, não foge a um outro apontamento de realidade trazido no mesmo art. $3^{\circ}$, como caracterizada pela pobreza, marginalização e desigualdades sociais e regionais a serem reduzidas.

Um padrão se caracteriza por um modelo reconhecido para aferir bens materiais ou imateriais, coisas ou mesmo instituiçôes. Já a melhoria supóe uma posição antecedente abaixo do padrão e que busca uma perfectibilidade. O melhor é uma referência de qualidade mais elevada ao que lhe é comparado. Sua expressão 
reiterada indica um anseio permanente e de finalidade sempre (re)posta em níveis cada vez mais superiores.

Mas pode-se conjeturar que reside aqui algo mais. A insistência na dimensão ensino e na sua melhoria aponta para o reconhecimento entredito de que os resultados da educação escolar não possuem uma situação recomendável. Essa preocupação reiterada contrasta com o horizonte que demanda melhoria, subjacente aos princípios norteadores da educaçấo escolar. Estamos no terreno da construção de um caminho. Se este é o horizonte, é porque o real dele se distancia, o que não significa uma mera constatação já que construir implica um movimento por avanços progressivos e cumulativos.

Certamente pode-se, então, perquirir por uma aproxima afirmativa do que seja a qualidade.

Para a consecução desta qualidade há alguns pontos fundamentais para a qualidade em educação: as condições de trabalho dos 2.500 .000 de docentes ${ }^{4}$ das 220.000 unidades escolares, nos 27 Estados da União, nos mais de 5.500 municípios. Sempre pressionando por salários mais dignos, tais docentes não usufruem de jornada integral e, nos mais diferentes diagnósticos, muitos sofrem de desistência laboral. Formados há como licenciados que se deslocam para outros nichos do mercado profissional ao invés do exercício da docência. Uma formação continuada que fuja do cursos pontuais ainda é um horizonte distante quando se pensa nesses grandes números. Sem uma dignificação salarial, sem uma formação continuada, a avaliaçấo de desempenho, legalmente prevista, tenderá mais para uma visão punitiva do que para a reiterada melhoria. ${ }^{5}$

A formaçáo de docentes levada adiante nos estabelecimentos de ensino superior, ressalvadas exceçóes exitosas, ainda está longe de considerar o campo real de trabalho onde os profissionais vão se inserir e as exigências necessárias para uma atuação profícua e coletiva.

Nossa tradição de jornada escolar para os alunos não ultrapassa as 4 horas legais, apesar do aumento de 180 para 200 dias letivos e do consenso internacional de que hora é hora de 60 minutos. Com isto se pretende que nossos estudantes saiam da escola com aprendizagens sólida e significativas. Como diz Gatti (2013, p. 677):

O escopo dos processos educativos é mais amplo e é essencial à coesão social e à realizaçáo das pessoas na sociedade contemporânea. Por essa razão não basta incluir crianças e jovens na escola, é necessário garantir formação e aprendizagens significativas para a vida social. 
E resta ainda a situação básica determinada pelo financiamento a fim de que se realize o disposto no art. 75 da LDB:

A ação supletiva e redistributiva da União e dos Estados será exercida de modo a corrigir, progressivamente, as disparidades de acesso e garantir o padrão de qualidade do ensino.

Par. 10 A ação a que se refere este artigo obedecerá a fórmula de domínio público que inclua a capacidade de atendimento e a medida do esforço fiscal do respectivo Estado, do Distrito Federal ou do Município em favor da manutenção e do desenvolvimento do ensino.

Par. 20 A capacidade de atendimento de cada governo será definida pela razão entre os recursos de uso constitucionalmente obrigatório na manutenção e do desenvolvimento do ensino e o curso anual do aluno, relativo ao padrão mínimo de qualidade.

A tarefa que nos acomete enquanto estudiosos e pesquisadores da educação com qualidade é dupla: buscar um conceito de qualidade cuja linguagem nos permita fazer uma leitura do real. Como um princípio conceitual, genérico e abstrato, a qualidade ajuda a esclarecer e organizar o real existente em novas bases.

A capacidade de mobilização de uma ideia política reside justamente nos seus conteúdos abstratos. Aliás, a abstração é fonte fundamental de sua força, porque permite que os conteúdos de determinados princípios gerais possam ganhar redefiniçóes inesperadas, e, portanto, a questão dos direitos será sempre uma construção imperfeita e inacabada. (REGO, 2006)

Ora, é preciso sair de uma situação que pede por melhoria. Sair, eis a questão. E para que tal saída se concretize face aos desafios, cumpre uma união de esforços, um pacto em que de comum acordo se opte por uma via de superação. Ficar no status quo é irracional. Buscar um pacto é a única saída racional.

\section{O Plano Nacional de Educação (PNE)}

Essa consciência de que ficar nesse estado é irracional já havia sido detectada em 1994 quando se dá a Conferência Nacional de Educação, em que as temáticas chaves foram o Plano Decenal de Educação para Todos e a busca de um Acordo Nacional de Educação para Todos. Nele se deu um consenso: Pacto pela Valorização do Magistério e Qualidade da Educação. Vários foram os compromis- 
sos assumidos seja por entidades da sociedade civil, de corporaçóes educacionais e de entidades governamentais de todos os entes federativos. ${ }^{6}$ Destaca-se, nesse pacto, a firme resoluçáo de pôr em evidência o papel do professor, sua qualificação profissional ante as necessidades básicas da aprendizagem e sua valorização face às condiçôes de trabalho.

Contudo, o governo que se seguiu estreitou os termos desse pacto do qual se poderia dizer que tinha aspectos rousseaunianos e os efetivou de tal modo que a União pouco cumpriu de seu papel em matéria educacional. Por ela, a União deveria exercer sua função redistributiva e supletiva, de forma a garantir equalização de oportunidades e padrão minimo de qualidade do ensino.

A tradução do Pacto de 1994 por meio do Fundo de Manutenção e Desenvolvimento do Ensino Fundamental e Valorizaçáo do Magistério (Fundef) representou a formalização de alguns aspectos daquele pacto. Com isso, houve um maior disciplinamento dos recursos vinculados e agora também sub-vinculados, inclusive para efeito de cálculo da média salarial dos docentes, e criaram-se os Conselhos de Controle Social dos recursos. O estreitamento se deu não só pela menor disposição de diálogo como também pelo não cumprimento de desembolso de recursos claramente definidos na lei n. 9.424/96, lei regulamentadora da Emenda Constitucional n. 14/96, encaminhada e defendida pela base governamental.

A ampliação do Fundef pelo Fundo de Manutenção e Desenvolvimento da Educação Básica e de Valorização dos Profissionais da Educação (Fundeb) por meio da Emenda Constitucional 53/2006 e da Lei n. 11.494/97, preservou pontos positivos do Fundef, ampliou sua abrangência para a educaçáo básica em seus níveis e modalidades, dispôs prazo para fixar, em lei específica, piso salarial profissional nacional para os profissionais do magistério público, explicita em valores pecuniários a complementação da União, aperfeiçoa os Conselhos de Controle do Fundo, reitera a obrigaçáo dos planos de carreira e remuneraçáo com capacitação profissional em que a formação continuada deve promover a qualidade do ensino.

O segundo é o Plano de Desenvolvimento da Educação (PDE) no qual o MEC assume um protagonismo compartilhado com os poderes públicos dos outros entes federativos. Nesse Plano, metas objetivas serão tomadas a partir de informaçôes e dados trazidos pelas avaliaçôes e indicadores feitos há 10 anos na Educação Básica. Essas metas, pactuadas por adesão com os entes federativos, terão o seu foco voltado para a aprendizagem e seus resultados com apoio na formação continuada. Este PDE, a rigor, foi uma iniciativa importante do MEC visando ser uma ação ersatz face ao fracasso do Plano Nacional de Educação, 2001-2011.

A partir daí, ficou claro aos educadores e gestores que o mandato constitucional do art. 214 não poderia ficar sem uma resposta consequente. Era preciso levar adiante aquele mandamento. Ora, uma meta do PNE 2001-2011 era a da realização de uma Conferência Nacional de Educação que avaliasse o PNE em 
curso e projetasse um novo. A Conferência, ocorrida em 2010, se deu já sob a égide de uma importantíssima emenda constitucional: a emenda constitucional n. 59/09. Ela trouxe novos dispositivos capazes de dar um outro alento à qualidade da educação. Ressalte-se a ampliação da obrigatoriedade na faixa etária entre 4 e 17 anos, da extensão dos programas suplementares a toda educação básica e respectivos recursos como elementos constantes da garantia de padráo de qualidade e equidade, nos termos do plano nacional de educação. Já o caput do art. 214 passou assim a vigorar:

A lei estabelecerá o plano nacional de educação, de duração decenal, com o objetivo de articular o sistema nacional de educação em regime de colaboração e definir diretrizes, objetivos, metas e estratégias de implementação para assegurar a manutenção e o desenvolvimento do ensino em seus diversos níveis, etapas e modalidades por meio de açóes integradas dos poderes públicos das diferentes esferas que conduzam a:

$[\ldots]$

VI - estabelecimento de meta de aplicação de recursos públicos em educação como proporção do produto interno bruto.

Desse modo, a obrigação de um novo PNE teria que ser articulada ao Sistema Nacional de Educação. Esta CoNAE de 2010 contou com ampla participação de educadores e gestores. Como consequência, à vista da intensa cobrança de um novo PNE, por sinal constitucionalmente previsto, o presidente Lula [N.E.: Luiz Inácio Lula da Silva, 35º Presidente da República Federativa do Brasil, 01.01.2003 a 01.01.2011] encaminhou ao Congresso Nacional o Projeto de Lei 8.035/11, referente a um novo Plano Nacional de Educação, a fim de passar pelo processo legislativo. Este projeto desencadeou, de um lado, a presença de especialistas, associaçóes, educadores nas audiências públicas das Comissões do Congresso Nacional (Câmara e Senado) e, de outro, uma intensa mobilização desde os Municípios, passando pelos Estados e chegando a Brasília. Uma outra lei importante é sancionada em 2013. Trata-se da lei n. 12.858 que dispóe sobre a destinação de parcela da exploração do petróleo e do gás natural exclusivamente para a educação pública, com prioridade para a educação básica.

A Conae deveria ocorrer em fevereiro de 2014 como mais um processo em vista da aprovação do PNE. Entretanto, ao governo interessava uma Conae após a aprovação do PNE. Com o retardamento da aprovação do PNE no Congresso, a Conae ficou para o mês de novembro. A rigor, o PNE só foi aprovado em junho e sancionado pela presidente Dilma Rousseff como lei n. 13.005/2014. Esta lei, retoma em seu art. $2^{\circ}$, IV, a melhoria da qualidade da educação e no VII vocaliza o estabelecimento de meta de aplicação de recursos públicos em educação como 
proporção do Produto Interno Bruto - PIB, que assegure atendimento às necessidades de expansão, com padrão de qualidade e equidade.

Quando se compara esta lei, que sancionou o PNE, com o projeto de lei n. 8.035/2010 vê-se que houve significativas alteraçóes que podem conduzir a uma estratégia de colaboração fundamental para uma educação de qualidade. Entre outros dispositivos cumpre dar destaque a três parágrafos do art. 7o. que criam instâncias interfederativas para dar sequência ao PNE. Trata-se do regime de colaboração que envolve os sistemas de educação dos entes federados e, por consequência, abrange também a rede privada. E destas instâncias, ao lado de outras, que se viabiliza um caminho de modo a alcançar as metas do PNE sob suas estratégias. Ei-las:

\50 - Será criada uma instância permanente de negociação e cooperação entre a União, os Estados, o Distrito Federal e os Municípios.

$\$ 6$ o - O fortalecimento do regime de colaboração entre os Estados e respectivos Municípios incluirá a instituição de instâncias permanentes de negociaçáo, cooperação e pactuação em cada Estado.

$\$ 7$ o - O fortalecimento do regime de colaboração entre os Municípios dar-se-á, inclusive, mediante a adoção de arranjos de desenvolvimento da educação.

É deveras importante atentar para estes parágrafos. Eles são uma novidade nesta trajetória já longa de busca de um regime de colaboração. As palavras são fortes dentro da ciência política: negociação, cooperação e pactuação. Todas elas se voltam para a articulação interfederativa por cujas mesas deverá escoar a implementação das políticas educacionais.

Já o regime de cooperação, constante do art. 23, \único, da Lei Maior, abrange apenas os entes federados. Este regime é distinto do regime de colaboração, mas não se opóe a este, pelo contrário, são complementares. A proposição deste regime de cooperação foi levada ao Congresso Nacional por meio do parlamentar Ságuas Moraes (PT/MT) e já está tramitando dentro do processo legislativo sob a sigla PLP/413/2014. ${ }^{7}$

Com o PNE, com a determinação de feitura dos planos estaduais e municipais até junho 2015, com o projeto de constituição de um sistema nacional de educação até 2016, com o projeto de lei complementar do regime de cooperação, espera-se, finalmente, poder se resgatar a ampliação do acesso e que tal se veja revestido do ansiado padrão de qualidade. 


\section{Conclusão}

Se tais medidas forem articuladas entre si, se a União mais uma vez não descumprir os termos desse novo pacto, se houver vontade de efetivar tais propósitos e metas, se houver um aumento da relação PIB/educação em vista de uma expansão qualificada, é possível dizer que estamos vislumbrando uma saída racional para um direito proclamado como direito social (art. $6^{\circ}$ da Constituição), com padrão de qualidade como direito de todos e dever do Estado entre cujos princípios norteadores está tanto o resguardo da cidadania, quanto um dos pilares dos direitos humanos.

Eis, pois, que a Conae e seus impactos sobre o Congresso e sobre os sistemas, representam uma oportunidade rara e histórica de o Brasil superar a pesada herança do passado excludente e lançar políticas que nos ponham no caminho de mudanças atuais na educação brasileira que molde uma verdadeira educação de qualidade.

Se esta herança pesada do passado e o caráter necessário e atual de uma educação de qualidade, representados, de um lado, pelo não cumprimento das promessas contidas no ordenamento jurídico nacional e internacional, e de outro, pela urgência pedida pela sociedade em vista da qualidade, nasceram da ação dos homens de tantas geraçôes passadas, é da ação consciente dos educadores de hoje que devem ser construídas as balizas de uma educação escolar que tenha a cidadania e os direitos humanos como pilares de sua realização.

\section{Notas}

1. Até a aprovação da Emenda Constitucional n. 45/2004, os tratados internacionais eram incorporados ao ordenamento jurídico do país no âmbito da legislação infraconstitucional.

2. É preciso distinguir entre uma Declaração e um Tratado. A primeira é uma proclamação solene a propósito de um direito e exprime a vontade de um Estado de pô-lo em prática. O segundo é um acordo formal concluído entre sujeitos de direito internacional público como os Estados. Tais sujeitos que assinam o Tratado se obrigam a o respeitar e o efetivar mediante obrigaçóes pertinentes. Cf. Objetivo Estratégico n. II do PNDH/2010 com relaçáo ao monitoramento dos compromissos internacionais assumidos pelo Brasil neste assunto. Para uma dimensão jurídica internacional, cf. Dupuy e Kerbrat, 2012. Por uma análise crítica dos direitos humanos, cf. Santos, 2013.

3. Cf. Art. 3o , IX; art. 4º. IX; art. 7o. II, art. 9o.,VI; art. 47, §. 4o.; art. 70, IV; art. 71, I; art. 74; art. 75 , caput; $\$ 2$ o da atual LDB.

4. Funções docentes.

5. Para análises críticas da avaliação da educação em nosso país, cf. Campos, 2013; Dourado e Oliveira, 2009; Freitas, 2005 e Oliveira, 2006.

6. Para maiores detalhes, cf. Vieira, 2000, especialmente pgs. 100 ss.

7. O relator na Comissão de Educação é Glauber Braga (PSB/RJ). 


\section{Referências}

BEISIEGEL, C. de R. Política e educação popular: a teoria e a prática de Paulo Freire no Brasil. Brasília; LiberLivro, 2008.

BOBBIO, N. A era dos direitos. Rio de Janeiro: Campus, 1992.

BOVERO, M. Contra o governo dos piores: uma gramática da democracia. Rio de Janeiro: Campus, 2002.

CAMPOS, M. M. Entre as políticas de qualidade e a qualidade das práticas. Cadernos de Pesquisa, São Paulo, v. 43, n. 148, jan./abr. 2013, p. 22-43.

DOURADO, L.; OLIVEIRA, J. F. A qualidade da educação: perspectivas e desafios. Cadernos Cedes, Campinas, v. 29, n. 78, maio/ago., 2009, p. 201-215.

DUPUY, P.; KERBRAT, Y. Droit International Public. Paris: Dalloz, 2012.

FREITAS, L. C. Qualidade negociada: a avaliação e contra-regulação na escola pública. Educação e Sociedade, Campinas, v. 26, n. 92, out/dez., 2005, p. 911-933.

GATTI, B. Desafios para a qualidade da educação básica. IN: ASSOCIAÇÃO BRASILEIRA DE MAGISTRADOS, PROMOTORES DE JUSTIÇA E DEFENSORES PÚBLICOS DA INFÂNCIA E ADOLESCÊNCIA. Justiça pela Qualidade na Educação. São Paulo: Saraiva, 2013.

OLIVEIRA, R. P. Estado e Politica Educacional no Brasil: desafios do século XXI. Tese de Livre Docência, Faculdade de Educação, Universidade de São Paulo, 2006 (mimeo.).

RANIERI, N. B. S. O direito educacional no sistema jurídico brasileiro. In: ASSOCIAÇÃO BRASILEIRA DE MAGISTRADOS, PROMOTORES DE JUSTIÇA E DEFENSORES PÚBLICOS DA INFÂNCIA E ADOLESCÊNCIA. Justiça pela Qualidade na Educação. São Paulo: Saraiva, 2013.

REGO, W. D. L. Intelectuais, Estado e Ordem Democrática: notas sobre as reflexôes de Florestan Fernandes. In: RIDENTI, M.; BASTOS, E. R.; ROLLAND, D. (Orgs.). Intelectuais e Estado. Belo Horizonte: Ed. UFMG, 2006.

SANTOS, B. S. Se Deus fosse um ativista dos direitos humanos. São Paulo: Cortez, 2013.

SOUZA, S. Z. Concepções de qualidade da educação básica forjadas por meio de avaliaçôes em larga escala. Avaliação. Campinas/Sorocaba, v. 19, n. 2, jul. 2014, p. 407-420.

VIEIRA, S. L. Política Educacional em tempos de transição. Brasília: Plano, 2000.

Recebido em 08 de dezembro de 2014. Aprovado em 27 de fevereiro de 2015. 